\title{
Participatory Infrastructuring of Community Energy
}

\author{
Andrea Capaccioli \\ University of Trento \\ via Sommarive, 9 \\ 38123 Trento (Italy) \\ andrea.capaccioli@u \\ nitn.it
}

\author{
Mela Bettega \\ University of Trento \\ via Sommarive, 9 \\ 38123 Trento (Italy) \\ mela.bettega@unitn.i \\ $\mathrm{t}$
}

Vincenzo D'Andrea

University of Trento

via Sommarive, 9

38123 Trento (Italy)

vincenzo.dandrea@u

nitn.it

\begin{abstract}
Thanks to renewable energies the decentralized energy system model is becoming more relevant in the production and distribution of energy. The scenario is important in order to achieve a successful energy transition. This paper presents a reflection on the ongoing experience of infrastructuring a sociotechnical system in which local communities can manage renewable energies as a Common Pool Resources. We explore how to create a space for citizens' participation in a continuous process of design for energy management. Objectives of the paper are: i) to clarify how Participatory Design could support the sustainability and the effectiveness of an alternative, ii) to present an experimentation with renewable energy as CPR as an alternative model to the actual vision of the energy system. Preliminary results reported in this paper suggest that a Participatory Design process can be valuable for communities in order to establish new energy management models.
\end{abstract}

\section{CCS Concepts}

\section{- Human-centered computing Participatory design}

\section{Keywords}

Sustainability; Energy Infrastructuring; Commons

\section{INTRODUCTION}

The COP21 Paris Conference brought to a wider audience the issues of climate change, global warming, energy consumption, $\mathrm{CO}_{2}$ emissions and the goals that we need to achieve in order to avoid a "catastrophic" future for humanity. These issues are nowadays at the center of political debate and they will need answers in the near future by countries and institutions, as much as by citizens and communities. European institutions have already declared and recognized the energy transition to a low carbon society as a goal to achieve in the near future [6]. These declarations are contradicted however through interventions such as the commodification of energy and greenhouse gases through the creation of new markets, opening the possibility for a financial speculation [7]. In our perspective, within this vision of the energy transition, the central rhetoric discourse in Europe around energy and emissions issues, involves just a shift from one source of energy to another one. The status quo is mainly preserved with only small changes for the social and economic actors involved in the energy value chain. However, this process could be the opportunity to rethink and redesign the electric production and distribution network and to enable new practices for a greener, more sustainable and socially accepted use of energy. An

\footnotetext{
Permission to make digital or hard copies of part or all of this work for personal or classroom use is granted without fee provided that copies are not made or distributed for profit or commercial advantage and that copies bear this notice and the full citation on the first page. Copyrights for third-party components of this work must be honored. For all other uses, contact the Owner/Author.

Copyright is held by the owner/author(s).

PDC'16, August 15-19, 2016, Aarhus, Denmark

ACM 978-1-4503-4136-3/16/08.
}

http://dx.doi.org/10.1145/2948076.2948089 alternative approach which takes advantage of the above mentioned opportunity, can be to consider energy as a commons and the energy transition as a transition not only toward a different source of energy, but to a different socio-technical paradigm [2]. Shifting from a paradigm of "energy obesity"[19] toward the creation of a new sustainable paradigm. While on one side there is a need for better and greener technologies, on the other side it is necessary to conciliate them with the life, the practices and the cultures of people and communities. A different approach can help such people and communities to increase awareness and to participate actively and successfully in infrastructuring an alternative to the way energy is conceived, managed and used.

The Participatory Design (PD) community has much to offer in this direction, in terms of design artifacts, but also in terms of looking at design as a future perspective, using the concept of PD as a form of infrastructuring that supports the creation of a fertile ground for a community of participants [11]. Effort has already been spent in using PD approaches for different kinds of interventions in the energy domain, such as enabling sustainable energy consumption [3] [16], for supporting networking among local energy initiatives [14] or for simulating micro-grid design [1]. In this paper we explore the infrastructuring of collective actions related to the energy network, which is a suitable example of broadening the view from technology development to knowledge production, sustainability and resilience [12]. PD is moving in this direction through binding together the concepts of commons and infrastructuring, as a way to go back to the original democratic ideals of PD [9]. Furthermore PD can be a force strengthening social practices nourishing the common [18].

The paper is structured as follows. Firstly, we present the theoretical framework behind the research. Secondly, we analyze the experience and the preliminary outcomes of an ongoing Participatory Design experience aiming to design an ICT platform for community energy management. Finally, we conclude by discussing the implications and highlighting points of attention for future work.

\section{INFRASTRUCTURING ENERGY AS A "COMMON"}

With the ongoing energy paradigm shift toward smart grids, we can also conceive energy, and renewable energies in particular, as a common good managed as Common Pool Resources (CPR)[15]. The challenge according to Dietz et al. [4] is to design institutional arrangements to help set the required conditions or tackle the challenges related to governance where the ideal conditions are not present: this is still the case of enabling the management of renewable energies as CPRs. Thus, within this scenario there is the need not only for an enabling technology to be imposed (such as in the dominant technology-driven view toward energy transition), but a socio-technical approach that 
takes into account the communities and the users to foster the creation of social acceptance of this new system [20].

Nowadays, most actors who support the actual highly centralized energy system (e.g. energy companies, authorities and regulations) do not fit into this possible future community energy scenario, where generation is distributed through smaller renewable energy plants and where the energy network is becoming highly decentralized and locally controlled. Both the institutional energy infrastructure and the physical one have been in place for decades and highly embedded in our lives. Smart-grid opens up the possibility of challenging the present condition in order to create an alternative by integrating the existing energy network with ICTs, generating new information. The electric grid becomes an information infrastructure [13]. The design and the implementation of such a thing define the power relations among the actors: citizens with a more decentralized network can have the possibility of sharing more control in terms of managing the energy source. That is why the involvement of communities plays a central role in the concrete design of the needed technologies to foster new sustainable practices. The focus on the community level of management is also seen as a way to increase the possibilities of reaching the critical mass that would have an impact on the energy transition goals [10]. The transition toward a community based energy paradigm, where distributed renewable energies are managed as CPRs, can be supported and encouraged by the PD community by enabling and fostering the "commoning practices"[12]. It becomes central to the role of the design process that needs to take place at a community-based level, as a process: for, with and by communities themselves [5].

\section{MAKING VISIBLE THE INVISIBLE: INFRASTRUCTURING NEW ENERGY RELATIONS}

The research presented in this paper is related to the ongoing experience of an EU/FP7 Project. It is an interdisciplinary project looking at the innovation of the energy system through the lens of a smart-grid. The project wants to integrate a new ICT platform to help local communities manage their local energy system. The focus is on the social and collective dimension of renewable energies. ICTs and their design shall serve as an empowering tool for the communities, helping them to reflect and to change their energy practices for the sake of the improvement of the community and to achieve collective self-defined goals. The Project has two pilot site areas, this paper focuses on the Italian area that comprises two rural municipalities in a northwestern Italian region: GreenVillage A, GreenVillage B. By September 2015293 people from 93 households were involved as participants in the pilot site area, all the participants are volunteers. The main feature of the Italian sites is the presence of two energy consortia that produce, distribute and sell electricity in the area of the three municipalities. The consortia are electric cooperatives born at the beginning of the $20^{\text {th }}$ century, they are membership-based focused on mutual cooperation. Their roots are deeply embedded within the local territory, where the consortia have strong social and economic relationships.

Due to their nature as cooperatives, members can participate in the governance of the companies. Both produce and distribute energy to their members by managing hydroelectric power plants and photovoltaic power plants. Most of the energy that the users of the involved municipalities consume is directly produced by the consortia or by the members through their photovoltaic panels. In case of a peak of consumption exceeding the available energy produced by the consortia, the needed energy is bought from the national grid at a higher cost and without a control over the sources.

We involved the participants in an ongoing PD process, with the aim of creating and establishing a community energy management, which go beyond the individual household level. This process is supported by the development of an ICT platform; participants are engaged in the definition of the features and the design of the interface. For this paper, we used the outcomes from 2 focus groups and 2 workshops carried out between January and June 2015, during the second year of the project. The outcomes from a second cycle of workshops, regarding the design of the platform interface, are not yet implemented and we are waiting for the release of the platform. While, from January to June 2016 we are currently carrying out a third cycle of workshops regarding the design and the implementation of the process for the allocation of the savings generated through the use of the ICT tools, with which participants will finance initiatives proposed for the sake of local communities.

\subsection{Renewables energies and community sense of belonging}

We conducted two focus groups, one in GreenVillage A and one in GreenVillage B to gather preliminary understandings of the local communities. The focus groups involved 10 and 9 participants respectively and lasted around two hours each. Three main points were discussed: i) sense of belonging to the community; ii) collective awareness about energy and environmental issues; iii) role of ICTs in energy interventions. A strong sense of identity and belonging to the community emerged from both focus groups. A heterogeneous and lively substrate of associations is presented in both municipalities; data from an explorative questionnaire, administered at enrollment, show that $76 \%$ of the respondents are members of at least one local association. At the beginning of 2015 the municipality of GreenVillage A completed a merging process with a nearby village. During the focus group participants discussed their community, highlighting how this process had been socially accepted and how the two municipalities already had administrative services in common. What was missing according to the participants was a more common sense of being a single community, instead of two separate communities. This has an influence on the willingness to put in common and share resources, such as energy. The two Consortia play a central role in the communities, as historical actors within the municipalities. During both the focus groups participants expressed a sense of pride for what the Consortia do. In GreenVillage B focus group participants told us the story of the first light bulbs installed more than a century ago, and what that meant for such a rural and isolated village. Furthermore, due to the membership and consortium-based way in which electric energy is managed in GreenVillage A and GreenVillage B, participants highlighted a high level of energy awareness. There is a good knowledge about energy market dynamics and about the impact of renewable energies. One of the key issues, which emerged in both focus groups is the lack of understandable and reliable information regarding the effectiveness of behavior perceived as virtuous. In both focus groups the idea of receiving concrete and verified suggestions, about how to improve practices for energy efficiency was discussed. Also, they reported a lack of information regarding the amount of energy consumed and produced by the community as a whole. They expressed the desire to do more for energy savings, while the two energy cooperatives could do more to spread information and create awareness. 


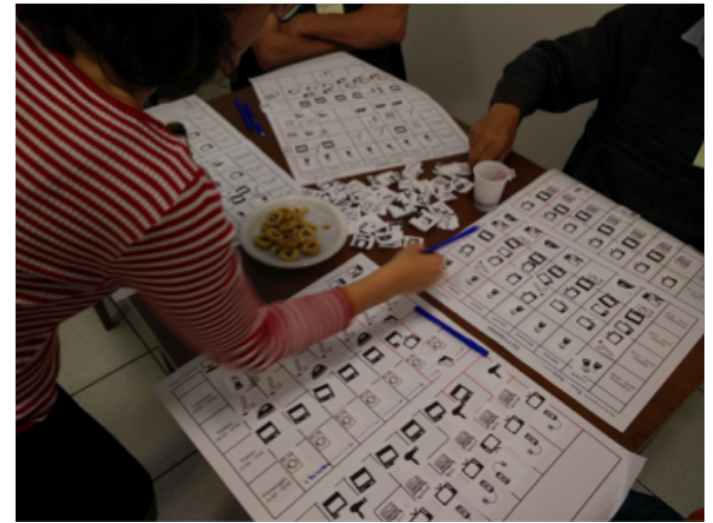

Figure 1 Participants to a workshop expliciting their weekly energy practices, May 2015

During the focus groups we asked about the possible use of saved energy for collective purposes. Participants reported more than one concern, such as: "how to correctly measure the energy saved?", "how to transfer the savings?" and "how to predict the possible savings in order to plan how to use them?" The major concern expressed was about the need for accountability of the whole process. In a certain way, the participants were expressing the need to see the first of the five conditions described by Dietz et al implemented [4]: the monitoring of the energy and its use. From the ICTs point of view, they expressed concern at dealing with an "enslaving" technology, which forces them to constantly monitor, such as for the use of already existing Apps and services like social networks. A technology that requires small efforts and no duty of a constant monitoring would be best accepted.

\subsection{Co-Designing tools for collective management of energy}

In May 2015 we carried out one workshop in GreenVillage A (17 participants) and one in GreenVillage B (9 participants). The initial part of the workshop was meant to prime the participants [17] in order to bring out the deep relationships that we have with energy, and how its use is spread across our day. We inquired about this dimension asking the participants to complete a calendar board with their actions related to household electricity use during the previous week (see Figure 1). Then, while looking at their filled in board, we asked them to reflect on the reasons that led their electricity consumption habits and on the possible drivers to change them in order to improve their consumption habits. The second part of the workshop was intended to work on a plausible future scenario that reflected the energy situation of the two municipalities and the use case scenario we developed in collaboration with the consortia and project partners. This was meant to set the users in a future situation in order to generate design concepts [17] helping the realization of such a scenario. The story of a fictitious village improving the collective energy consumption by adopting an ICT platform and a new kind of dynamic price scheme for the optimization of locally produced energy. The story highlights the idea of considering energy as a common good. Starting from the given scenario we asked the participants to reflect on two points: problems and difficulties they could experience in such a scenario and possible solutions to these problems. The final activity of the workshop was to combine the initial reflection of their consumption habits with the difficulties and the solution of the futuristic scenario. Divided into groups, participants came up with possible stories of families, developed through the use of the different things they thought about during the previous activities. For the participants finding the possible connections between the reality and the scenario was a challenging activity, and they came up with stories leading to different goals: energy savings for the families, increased environmental awareness, overcoming difficulties in changing energy practices due to day to day commitments.

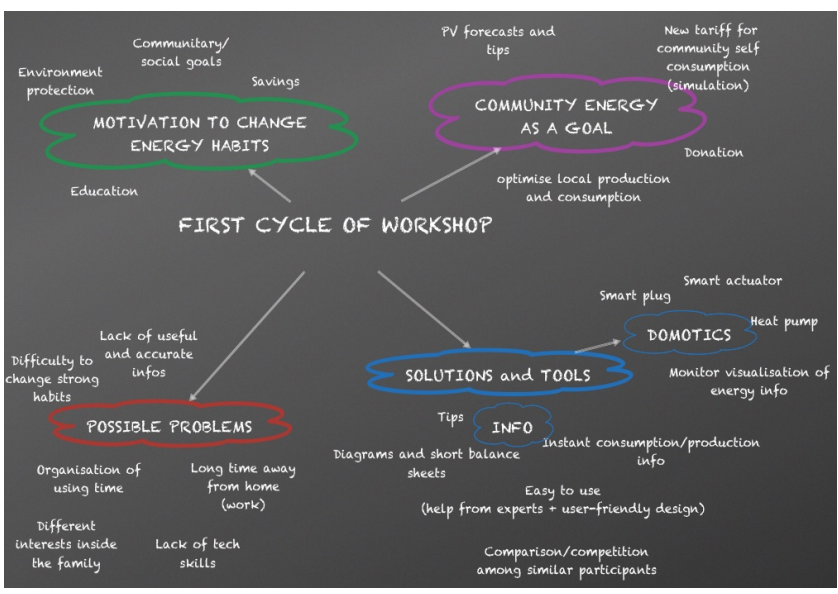

Figure 2 Diagram of the outcomes from the workshops

The results of the workshop are summarized in a diagram (see Figure 2). As possible problems they recognized technical aspects such as the lack of accurate information, but the main problems are mostly related to everyday practices. The participants considered routines, habits and different interests inside the family as major concerns about a successful implementation of the proposed scenario. The underlying motivations to overcome the possible problems are related to achieving community and environmental goals, with the focus also on possible savings. So, while the identified problems are at the household or at the individual level, the motivations to change reside to a community and society level. This duality emerged during the workshops, where participants expressed also, as possible solutions, two categories of technology: domotics and automation solutions, and information tools. The implementation of ICTs is also combined with the creation of new social practices to reach the community energy goal: to implement an energy donation mechanism it is necessary to find a common agreement within the community on how to manage the process and which kind of organization is needed to have a clear accountability. Indeed, this first part of the project opened the possibility for creating the conditions for the participation to energy management at the community level. Such goal is related with the design of an effective ICT platform, embedding both the household and the collective level.

\section{CONCLUSIONS}

Energy is a key factor for societies, and its abundance in the last centuries is one of the factors that led to the impressive development of our society since the industrial revolution, but it is also a factor for all the major environmental downsides that we are now facing [19]. The infrastructuring of collective actions for energy management, as explored and presented by experiences described in this paper, has provided an example for imagining an alternative future going "beyond capital" [8]. The communities participating are fully aware of the impact of climate change and they want to take a stand with concrete actions. They are helped by the cooperative values, which are embedded in the history of the consortia and widely spread among the members and their communities. They can base their participation in the community energy management upon an existing socio-technical context already based on different values rather than only an economic 
one. The existent electric infrastructure, which is already in place and hardly modifiable without hard intervention, can be modelled and adapted to the local social context by the means of ICTs, opening new possibilities. The PD community can help experiences like these to design a sustainable alternative, creating new relationships among the actors involved. This creates a space for citizens' participation in a continuous process of design for energy management. An important question that emerged from the activities described in the paper was how to make this space sustainable in the future for citizens and communities who want to control their energy. The deployment phase and the evaluation of the process at the end of the project could bring more insights about the issues of sustainability and appropriation of energy as CPR. So, the answers will arrive from the citizens participating in imagining their own possible future.

\section{ACKNOWLEDGMENTS}

This work has been supported by EU-FP7 programme through the project CIVIS (no. 608774).

\section{REFERENCES}

[1] Abdullah, M.A. and Kennedy, S. 2015. A Simulation Gaming Approach to Micro-grid Design and Planning: Participatory Design and Capacity Building. Decentralized Solutions for Developing Economies. S. Groh, J. van der Straeten, B.E. Lasch, D. Gershenson, W.L. Filho, and D.M. Kammen, eds. Springer International Publishing. 79-88.

[2] Byrne, J., Martinez, C. and Ruggero, C. 2009. Relocating Energy in the Social Commons: Ideas for a Sustainable Energy Utility. Bulletin of Science, Technology \& Society. 29, 2 (Apr. 2009), 81-94.

[3] Dick, H., Eden, H., Fischer, G. and Zietz, J. 2012. Empowering Users to Become Designers: Using Metadesign Environments to Enable and Motivate Sustainable Energy Decisions. Proceedings of the 12th Participatory Design Conference: Exploratory Papers, Workshop Descriptions, Industry Cases - Volume 2 (New York, NY, USA, 2012), 49-52.

[4] Dietz, T., Ostrom, E. and Stern, P.C. 2003. The Struggle to Govern the Commons. Science. 302, 5652 (Dec. 2003), 1907-1912.

[5] DiSalvo, C., Clement, A. and Pipek, V. 2012. Participatory Design For, With, and By Communities. International Handbook of Participatory Design. J. Simonsen and T. Robertson, eds. Routledge. 182-209.

[6] European Commission A Roadmap for moving to a competitive low carbon economy in 2050.

[7] Frame, D.J. 2011. The problems of markets: science, norms and the commodification of carbon. The Geographical Journal. 177, 2 (Jun. 2011), 138-148.

[8] Hakken, D., Teli, M. and Andrews, B. 2015. Beyond Capital: Values, Commons, Computing, and the Search for a Viable Future. Routledge.
[9] Karasti, H. 2014. Infrastructuring in participatory design. Proceedings of the 13th Participatory Design Conference: Research Papers-Volume 1 (2014), 141-150.

[10] Karnouskos, S. 2011. Communityware smartgrid. 21st International Conference and Exhibition on Electricity Distribution (CIRED 2011), Frankfurt, Germany (2011), 6-9.

[11] LeDantec, C.A.L. and DiSalvo, C. 2013. Infrastructuring and the formation of publics in participatory design. Social Studies of Science. 43, 2 (Apr. 2013), 241-264.

[12] Marttila, S., Botero, A. and Saad-Sulonen, J. 2014. Towards Commons Design in Participatory Design. Proceedings of the 13th Participatory Design Conference: Short Papers, Industry Cases, Workshop Descriptions, Doctoral Consortium Papers, and Keynote Abstracts Volume 2 (New York, NY, USA, 2014), 9-12.

[13] Neumann, L.J. and Star, S.L. 1996. Making Infrastructure: The Dream of a Common Language. PDC. (Jan. 1996), 231-240.

[14] Nieusma, D. 2000. From Database Design to Community Mobilization: PD in Sri Lanka's Energy Sector. PDC. (Jan. 2000), 314-317.

[15] Ostrom, E. 1990. Governing the commons: The evolution of institutions for collective action. Cambridge University Press.

[16] Prost, S., Mattheiss, E. and Tscheligi, M. 2015. From Awareness to Empowerment: Using Design Fiction to Explore Paths Towards a Sustainable Energy Future. Proceedings of the 18th ACM Conference on Computer Supported Cooperative Work \&\#38; Social Computing (New York, NY, USA, 2015), 1649-1658.

[17] Sanders, E.B.-N., Brandt, E. and Binder, T. 2010. A Framework for Organizing the Tools and Techniques of Participatory Design. Proceedings of the 11th Biennial Participatory Design Conference (New York, NY, USA, 2010), 195-198.

[18] Teli, M. 2015. Computing and the Common. Hints of a new utopia in Participatory Design. Aarhus Series on Human Centered Computing. 1, 1 (Oct. 2015), 4.

[19] Tertzakian, P. and Hollihan, K. 2009. The End of Energy Obesity: Breaking Today's Energy Addiction for a Prosperous and Secure Tomorrow. Wiley.

[20] Wolsink, M. 2012. The research agenda on social acceptance of distributed generation in smart grids: Renewable as common pool resources. Renewable and Sustainable Energy Reviews. 16, 1 (Jan. 2012), 822-835. 